\title{
A STUDY OF FRACTURES OF THE ANKLE WHICH ULTIMATELY REQUIRED ARTHRODESIS
}

\author{
J. R. Pearson, F.R.C.S.
}

Robert Jones and Agnes Hunt Orthopaedic Hospital, Oswestry.

A DIFFICULTY of studying patients for ten or more years is that so many patients do not attend for examination, either because of a change of address, lack of desire to attend, or because of infirmity or death. A study of fractures of the ankle which, at a later date, required an arthrodesis, does give some indication of the long-term results. This group is, of course, highly self-selected, but the noteworthy feature is that these are all fractures which produce serious symptoms.

Sixty-five patients of the Manchester Royal Infirmary required this operation between 1949 and 1959 for the end-results of ankle fractures. Fifty-four of these patients were referred from other hospitals. This series gives, of course, no indication of the incidence of ankle joint fractures for which arthrodesis may becomc necessary, as the patients were referred from many hospitals to a University centre which, at the time, was making a special study of anthrodesis of the ankle. The usual indication for the operation was pain (sixty-two patients). Most (forty-five) of these ankles were judged to be the site of osteoarthritis, due possibly to irregularity of the ankle joint articular surface or of its mortise as a result of the injury.

The mean time before an anthrodesis was required where irregularity of the ankle joint was present, was fifteen years; the range was two-and-a-half years to twenty-eight years. This is in contrast to patients who required an arthrodesis because of widening of the ankle mortise-here the mean time was three yearsw and the range was one year to five years.

Five patients required arthrodesis after fracture in which there was comminution of the lower end of the tibia. Four of these fractures were compound. All these patientso had the arthrodesis performed within two years of the injury.

Two patients had the arthrodesis performed after a deformity had developed because of epiphyseal arrest, one seven years after the injury, the other twenty-two years afterwards

It would appear from this series of bacto results from ankle fractures that no case nigs be considered to have made a good recover. 6 until many years have elapsed. Fusion necessary in one case twenty-eight years aftes the fracture, despite a long initial perio $\Phi$ (twenty-five years) of painless function withoug disability. No particular type of ankle fracture was unduly represented in this group of "failures", but it would appear that inferio tibio-fibular diastasis makes the need fo arthrodesis appear earlier than in fractures. without this complication.

The obvious ill effect of comminution of the articular surface calls for no further comment 